\title{
Competency Based Training in Intensive Care Medicine in Europe. Creating the European intensivist: the nursing dimension
}

Hannah Barrett RN; BNurs (Hons), CoBaTrICE Research Nurse, University Department of Anaesthesia and Intensive Care, N5 Queen Elizabeth Hospital, Birmingham B15 2TH, UK. Julian F Bion MD, FRCP, FRCA, CoBaTrlCE Project Lead, Reader in Intensive Care Medicine, University Department of Anaesthesia and Intensive Care, N5 Queen Elizabeth Hospital, Birmingham B15 2TH, UK

E-mail: H.Barrett@bham.ac.uk

Key words: competence-based training intensive care medicine medical education

\section{SUMMARY}

* CoBaTrICE is a European research project to create a common training programme for doctors in intensive care medicine.

* CoBaTrICE provides a unique opportunity for critical care nurses to be involved in shaping the intensive care medicine consultants of the future.

\section{INTRODUCTION}

CoBaTrICE (competency-based training in intensive care medicine in Europe) is a unique initiative funded by the European Commission, which aims to create a common training programme for doctors in intensive care medicine based on the definition and acquisition of competence. This three-year project, currently in progress, will define the minimum standard of knowledge, skills and attitudes required for a doctor to be identified as a specialist in intensive care medicine.

The underlying principle of this project is the notion that a specialist in intensive care medicine trained in one European country should possess the same core skills and abilities as one trained in another, thereby guaranteeing a common minimum standard of clinical competence. The project will use consensus techniques to achieve this, providing a unique opportunity for individual doctors, nurses, allied health professionals, national organisations and the general public to shape the training of doctors in intensive care medicine.

\section{BACKGROUND}

Intensive care medicine shares the same problem as critical care nursing: there is no European minimum standard of education. The majority of European countries have training programmes in intensive care medicine; however, there is considerable variation in access to training, the duration and content of programmes and in the methods of assessment and accreditation (Bion et al. 1998). As a consequence, there is no formal consensus about the core skills and abilities that define a specialist in intensive care medicine.

In this era of increasing European mobility, Baktoft et al. (2003) highlight the logical necessity for all countries to agree common standards of education to judge the competence and training of critical care nurses. CoBaTrICE is applying this principle to medical education in intensive care.

Competency-based training, familiar to many nursing curricula, is a relatively new concept in medical education. It is a powerful outcome-based strategy that defines the level of knowledge, skills and attitudes required of doctors at different stages of training. Methods of teaching and the duration of training may vary, but the competencies, and the techniques employed to assess their acquisition, are clearly defined and common to all.

\section{METHODOLOGY}

The project is divided into four phases (see Figure 1). The first, a survey of international methods of intensive care medicine training, is currently in progress. Phase 2 started at the beginning of June 2004. This involves the identification of competencies expected of trainees and specialist doctors in intensive care medicine, using consensus methods (a modified Delphi process).

Critical care professionals from all disciplines, educators and professional/educational organisations across Europe are invited to submit suggestions for competencies between June-October 2004 via the internet (http://www.intensium.com/cobatrice/).

\section{Phases of CoBaTrICE: \\ Autumn 2003 - Autumn 2004 \\ Spring 2004 - Autumn 2005 \\ Spring 2005 - Spring 2006 \\ Autumn 2005 - Autumn 2006}

International survey of training in intensive care medicine Development of competencies using consensus techniques Linking competencies to a core curriculum and assessment criteria Linking competencies to educational resources

Figure 1. 
Concurrently, contributions from patients and families will be sought using survey techniques. From these suggestions, a nominal group will produce a draft of the minimum core competencies expected of a safe, independent practitioner. Following a period of consultation, the final competencies will be categorised to form the basis of the training programme.

During the third and fourth phases of the project, each competence will be linked to elements in a core curriculum (knowledge, skills and attitudes), assessment criteria and relevant learning materials. The outcome will be a web-based training programme that defines the core competencies of an intensive care medicine specialist, methods for their assessment and educational resources to support their acquisition.

\section{SIGNIFICANCE OF THE PROJECT FOR NURSING}

CoBaTrICE will be a flagship for other specialities and disciplines to follow as they harmonise standards of training and accreditation. This project offers a unique opportunity for critical care nurses to be involved in shaping the intensive care consultants of the future.

If you are still unconvinced that nurses can contribute to a medical training programme, remember that the knowledge, skills and attitudes of intensive care doctors are observed continuously by critical care nurses, who are at the forefront of patient care 24 hours a day. An experienced critical care nurse will have a significant insight into the knowledge and skills they consider to be fundamental to a specialist in intensive care medicine. In addition, nursing has long acknowledged the significance of behavioural competence on the quality of care of those affected by life threatening illness - knowledge and skills may be equal, but it is the attitude with which they are applied that makes all the difference. Now is your opportunity to highlight the behavioural expectations required of intensive care doctors. We urge you to be a part of this exciting project!

\section{GETTING INVOLVED}

We would like to receive as many suggestions as possible, from health care professionals and educators, for competencies (knowledge, skills and attitudes) that intensive care medicine specialists should have acquired by the end of their training. These suggestions can be submitted at http://www.intensium.com/cobatrice between June-October 2004. In addition, you can contribute by identifying educational resources and by spreading the word about the project, encouraging colleagues from all disciplines to participate. For further information, please visit the project website at www.esicm.org or contact the CoBaTrlCE research nurse via email: h.barrett@bham.ac.uk.

\section{REFERENCES}

Bion JF, Ramsay G, Roussos C, Burchardi H. (1998) Intensive care training and speciality status in Europe: international comparisons. Intensive Care Medicine 24(4): 372-377.

Baktoft B, Drigo E, Hohl ML, Klancar S, Tseroni M, Putzai P. (2003) A survey of critical care nursing education in Europe. Connect: The World of Critical Care Nursing 2(3): 85-87.

\section{NOTES}

CoBaTrICE partners: ESICM, University of Birmingham, Charles University Hospital, Intensium Oy and Picker Institute Europe.

\section{Sponsors}

CoBaTrICE is supported by a grant from the European Union Leonardo de Vinci programme. Additional supporter: GlaxoSmithKline. 